\title{
Adubação potássica em plantas de coberturas no sistema de plantio direto e efeitos na cultura da soja em sucessão
}

Hugo Henrique Andrade Meneghette, Edson Lazarini, João William Bossolani, Fabiana Lopes dos Santos, Izabela Rodrigues Sanches, Naira Quirino Biazi

Universidade Estadual Paulista - UNESP, Faculdade de Engenharia, Ilha Solteira, SP. E-mail: $\underline{\text { hugoh96@gmail.com }}$

\section{Resumo}

Estudos recentes demonstram que a adubação potássica em áreas adeptas do sistema de plantio direto resultam uma boa correlação com a produção de fitomassa de coberturas utilizadas em processo de rotação. $O$ presente trabalho teve como objetivo avaliar os efeitos da adubação potássica em três diferentes gramíneas e a eficácia residual para a cultura da soja em sucessão em sistema de plantio direto. $O$ experimento foi conduzido em área experimental pertencente a UNESP - FEIS, nos anos agrícolas de 2012/13 e 2013/14. O delineamento experimental utilizado foi o de blocos casualizados, sendo os tratamentos quatro doses de $\mathrm{K}\left(0,35,70,120 \mathrm{~kg} \mathrm{ha}^{-1}\right)$ com quatro repetições. Cada cobertura foi avaliada isoladamente totalizando três subprojetos. O solo da área é classificado como LATOSSOLO VERMELHO Distrófico de textura argilosa. O segundo ano de experimento foi negativamente influenciado pelas questões climáticas problemáticas na época do estudo. Em função dos tratamentos aplicados, maiores produções de fitomassa foram vistas para a sucessão com milho. A maior média para teor de $K$ foliar na soja foi observada em função na sucessão com sorgo. $\mathrm{O}$ teor de $\mathrm{K}$ na palhada destacou-se para as plantas de milheto. A maior produtividade de grãos de soja foi observada em área de sorgo.

Palavras-chave: Glycine max L.; nutrição mineral; matéria seca; produtividade de grãos.

\section{POTASSIC FERTILIZATION IN COVER PLANTS IN NO-TILL SYSTEM AND EFFECTS ON SOYBEANS CROP IN SUCCESSION}

\begin{abstract}
Recent studies shows that potassic in areas adept to the no-till system has a good correlation with phytomass production of the cover plants used in the rotation process. In this sense, the present work has as objective evaluate the effects of potassic fertilization realized in three different grasses and the residual efficiency for the soybean crop in succession in no-till system. The experiment was conducted in the farm of education, research and extension of UNESP - FEIS, in the agricultural years of 2012/13 and 2013/14. The experimental design used was the random blocks, with four doses of $K$ as treatments $\left(0,35,70,120 \mathrm{~kg} \mathrm{ha}^{-1}\right)$, with four repetitions. Each cover crop was evaluated in isolation, totalizing three subprojects. The soil of the area is classified as RED LATOSSOL Clay-textured distrophic. The second year of experiment was negatively influenced by the problematic climatic issues at the time of the study. Due to the treatments applied, higher phytomass yields were seen for maize succession. The highest average for leaf $K$ content in soybean was observed in function of the succession with sorghum. The $K$ content in the straw was outstanding for the millet plants. The highest grain yield of soybean was observed in sorghum area.
\end{abstract}

Keywords: mineral nutrition; dry matter; Glycine max L.; grain yield.

Introdução

O sistema de plantio direto (SPD) faz-se uma ferramenta de grande valor e importância quando se refere a recuperação, sustentabilidade e manutenção da capacidade produtiva dos solos manejados convencionalmente por longos 
períodos de tempo, ou de áreas degradadas em território nacional (TORRES et al., 2015).

A conservação de restos vegetais na superfície do solo em sistemas de produção agrícola, além de proteger o solo da radiação solar, promove dissipação de impacto das chuvas, redução de evaporação de água e auxilia no controle de plantas daninhas (SOUSA, 2013), além do potencial para restituir parte dos nutrientes extraídos do solo e os liberarem nas camadas superficiais através da decomposição de seus resíduos, promovendo uma ciclagem eficiente de nutrientes (PIRES et al., 2015).

A expansão agrícola no Cerrado observada nos últimos anos deu-se por solução parcial ou total de problemas como a formação e manutenção de palhada, correção das propriedades físicas e químicas ao longo do solo, mecanização agrícola, manejo de daninhas, entre outros. Entretanto, sob as condições climáticas inerentes deste bioma, tem sido difícil a formação e principalmente a manutenção de volume de palhada, em quantidade suficiente para proteger plenamente a superfície do solo (KLUTHCOUSKI et al., 2000).

Os resíduos culturais na superfície do solo criam uma importante reserva de nutrientes, cuja disponibilização pode ser de forma rápida e intensa, ou lenta e gradual, de acordo com as interações entre fatores climáticos, essencialmente precipitação pluvial, temperatura, atividade macro e microbiológica do solo, qualidade e quantidade do resíduo vegetal (SILVA et al., 2014).

De acordo com Foloni (2008), o K é o segundo nutriente mineral requerido pelas plantas em termos de quantidade e não possui função estrutural no metabolismo vegetal, permanecendo quase totalmente na forma iônica nos tecidos. Nos restos vegetais, não se incorpora às cadeias carbônicas da matéria orgânica no solo. Após a colheita ou senescência das plantas ele volta rapidamente ao solo em forma prontamente disponível para as culturas (PARENTE et al., 2016), fazendo da palhada um reservatório expressivo de $\mathrm{K}$ no curto prazo no plantio direto.

As necessidades de $\mathrm{K}$ para $\mathrm{O}$ ótimo crescimento das plantas situam-se na faixa de 20 a $50 \mathrm{~g} \mathrm{~kg}^{-1}$ da massa das partes vegetativas secas da planta, das frutas e dos tubérculos, entretanto as plantas têm a capacidade de absorver quantidade de $\mathrm{K}$ superior à sua necessidade, $\mathrm{O}$ que comumente é denominado consumo de luxo (TORRES; PEREIRA, 2008).

Segundo Silva (2014), a adubação potássica pode ser realizada tanto no sulco de semeadura quanto a lanço, sendo a aplicação a lanço realizada antes da semeadura e recomendada para solos de textura argilosa, com teores médios e bons de $\mathrm{K}$, e na aplicação de $\mathrm{K}$ no sulco de semeadura, alguns cuidados são recomendados a fim de reduzir o efeito salino na germinação de sementes (KAWAVATA, 2017).

Neste contexto, o objetivo do presente trabalho foi avaliar e quantificar os efeitos da adubação potássica e seu retorno potencial, realizada em três diferentes gramíneas, e a eficácia residual para a cultura da soja em sucessão em sistema de plantio direto.

\section{Material e Métodos}

O experimento foi desenvolvido no período de 2012-2014 em área experimental pertencente à Universidade Estadual Paulista (UNESP), Faculdade de Engenharia, Ilha Solteira-SP, localizada no Município de Selvíria-MS, apresentando como coordenadas geográficas $55^{\circ}$ $22^{\prime}$ de longitude Oeste de Greenwich e $20^{\circ} 22^{\prime}$ de Latitude Sul, com altitude de $335 \mathrm{~m}$. O solo da área experimental foi classificado como LATOSSOLO VERMELHO Distroférrico de textura argilosa, segundo classificação da EMBRAPA (2013). Antes da instalação do experimento em campo, foi realizada amostragem do solo na camada de 0-0,20 m para análise química, cujos resultados foram: $\mathrm{P}$ (resina) - $22 \mathrm{mg} \mathrm{dm}^{-3}, \mathrm{MO}-21$ $\mathrm{g} \mathrm{dm}^{-3}, \mathrm{pH}\left(\mathrm{CaCl}_{2}\right)-5,5, \mathrm{~K}-1,8 \mathrm{mmol}_{\mathrm{c}} \mathrm{dm}^{-3}, \mathrm{Ca}-$ $22 \mathrm{mmol}_{\mathrm{c}} \mathrm{dm}^{-3}, \mathrm{Mg}-19 \mathrm{mmol}_{\mathrm{c}} \mathrm{dm}^{-3}, \mathrm{H}+\mathrm{Al}-22$ $\mathrm{mmol}_{\mathrm{c}} \mathrm{dm}^{-3}, \mathrm{SB}-42,8 \mathrm{mmol}_{\mathrm{c}} \mathrm{dm}^{-3}, \mathrm{CTC}-64,5$ $\mathrm{mmol}_{\mathrm{c}} \mathrm{dm}^{-3}$ e V\% - 66 .

A precipitação, temperatura e umidade relativa média anual dos últimos 18 anos são de $1313 \mathrm{~mm}, 25{ }^{\circ} \mathrm{C}$ e $70-80 \%$, respectivamente (Portugal et al., 2015). O clima da região é Aw, de acordo com a classificação de Köppen, definido como tropical úmido, com estação chuvosa no verão e seca no inverno. $O$ experimento foi desenvolvido em condição de sequeiro. Os dados climáticos referentes ao período de condução do experimento encontram-se na Figura 1. 
Figura 1. Valores médios de precipitação e temperatura máxima e mínima durante a condução do experimento. Selvíria - MS, 2012-2014.

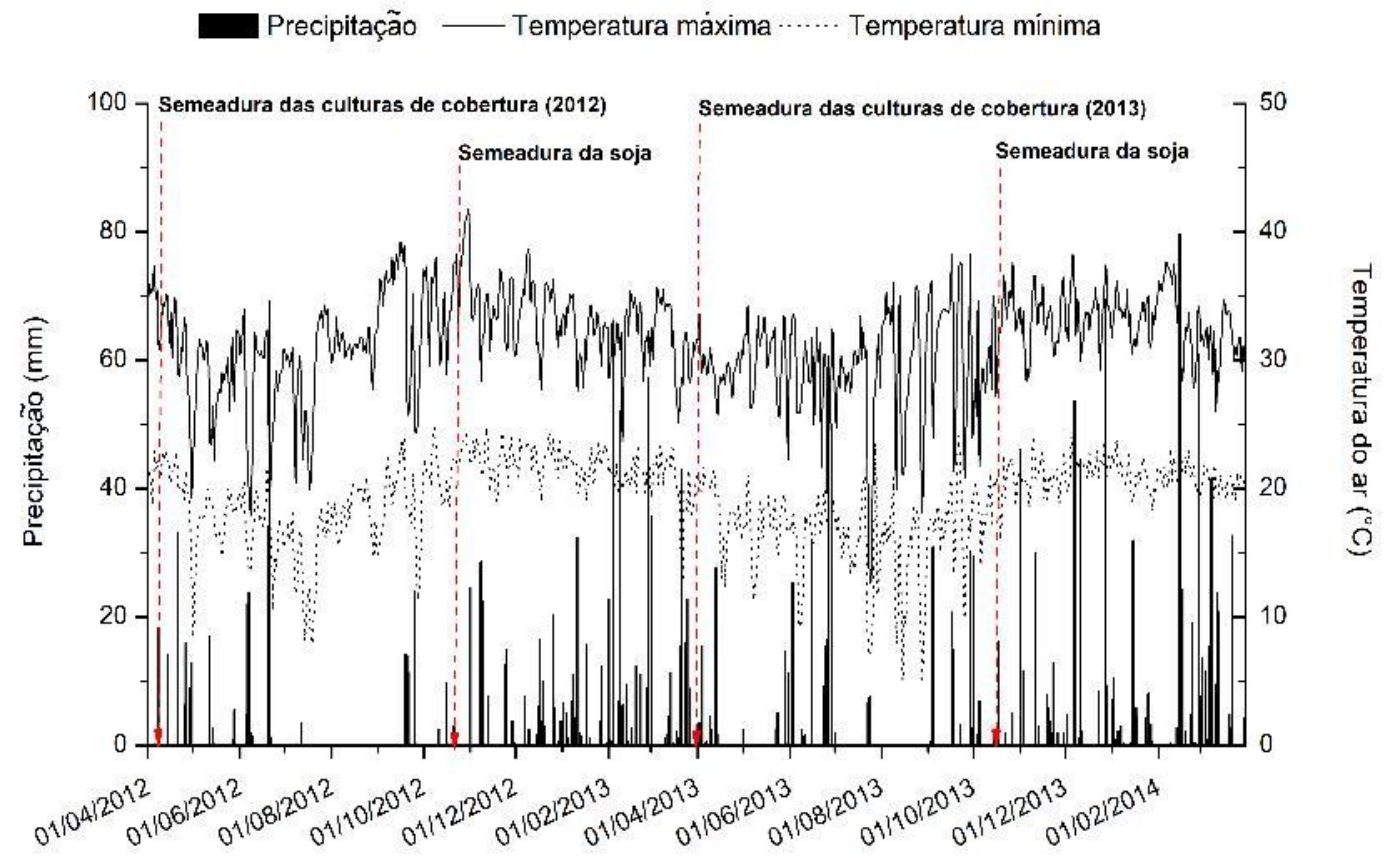

O delineamento experimental utilizado foi o de blocos ao acaso, com 4 repetições. Os tratamentos se constituíram de quatro doses de $\mathrm{K}_{2} \mathrm{O}$ aplicados antecipadamente em 3 plantas de cobertura, sendo milho (Zea mays L.), milheto (Pennisetum americanum L.) e sorgo (Sorghum bicolor L.), e ainda o efeito residual na soja (Glycine max L.) em sucessão. Cada cultura antecessora foi avaliada como um experimento diferente, totalizando 3 subprojetos. Foram utilizados na entressafra o milho, o sorgo e o milheto associados a quatro doses de $\mathrm{K}_{2} \mathrm{O}(0 ; 35$; 70 e $120 \mathrm{~kg} \mathrm{ha}^{-1}$ ) na forma de $\mathrm{KCl}\left(58 \%\right.$ de $\left.\mathrm{K}_{2} \mathrm{O}\right)$.

As semeaduras das culturas antecessoras foram realizadas sempre entre nos meses de abril de cada ano. O híbrido de milho utilizado foi o DKB 390 VTPRO 2, no espaçamento de 0,45m e com população esperada de 60.000 plantas ha ${ }^{-1}$. O sorgo utilizado foi o híbrido Rancheiro, no espaçamento de $0,45 \mathrm{~m}$ e população esperada de 150.000 plantas $\mathrm{h}^{-1}$. Para o milheto, a variedade utilizada foi BRS-1501 O espaçamento utilizado foi 0,34 $\mathrm{m}$ entre linhas e utilizou-se aproximadamente $20 \mathrm{~kg} \mathrm{ha}^{-1}$ de sementes. A adubação de base utilizada para todas as culturas antecessoras foi constituída superfosfato simples ( $18 \%$ de $\mathrm{P}_{2} \mathrm{O}_{5}$ e $10 \%$ de $\mathrm{S}$ ), na dose de $300 \mathrm{~kg} \mathrm{ha}^{-1}$. No milho e no sorgo, quando atingiram o estádio fenológico $V_{3 .}$, foi realizado adubação nitrogenada de cobertura, na dose de $70 \mathrm{~kg} \mathrm{ha}^{-1}$ de $\mathrm{N}$, na forma de ureia ( $45 \%$ de $N)$. No mês de setembro de cada ano foram manejadas todas as plantas remanescentes na área e posteriormente manejadas com rolo-faca.

As semeaduras da soja em ambos os anos de cultivo foram realizadas na segunda quinzena de outubro. A variedade utilizada foi a BRS Valiosa RR, no espaçamento de $0,45 \mathrm{~m}$ e população esperada de 250.000 plantas ha ${ }^{-1}$. O tratamento de sementes foi realizado com os fungicidas carboxin + thiram na dose de $250 \mathrm{~mL}$ do produto comercial $100 \mathrm{~kg}^{-1}$ de sementes. $\mathrm{Na}$ sequência, realizou-se a inoculação das sementes com inoculante líquido que possuía concentração de $5 \times 10^{9}$ células $\mathrm{mL}^{-1}$, utilizando-se $100 \mathrm{~mL}$ do produto comercial para $50 \mathrm{~kg}^{-1}$ de sementes. A adubação de base foi constituída por $330 \mathrm{~kg} \mathrm{ha}^{-1}$ de superfosfato simples ( $18 \%$ de $\mathrm{P}_{2} \mathrm{O}_{5}$ e $10 \%$ de $\mathrm{S}$ ).

As avaliações realizadas nas plantas de cobertura foram: massa de matéria seca (MMS), teor de K na palhada e seu retorno potencial. $\mathrm{Na}$ cultura da soja em sucessão, avaliou-se a produtividade e teor de $\mathrm{K}$ foliar. Para a MMS, após a dessecação, foi realizada uma amostragem da parte área, coletando-se uma linha de 1,0 de comprimento na área útil da parcela. O material obtido foi levado ao laboratório, lavado com água deionizada, segundo preconiza Jones Júnior et al. (1991) e acondicionado em estufa de circulação forçada a $65{ }^{\circ} \mathrm{C}$ por $72 \mathrm{~h}$ aproximadamente, sendo pesado posteriormente para efetivar os cálculos de matéria seca produzida $\left(\mathrm{kg} \mathrm{ha}^{-1}\right)$. Após secagem e pesagem, o material obtido foi moído em moinho tipo Willey, para determinação do 
teor de K segundo metodologia de Malavolta et al. (1997).

Para a soja em sucessão, foram avaliadas as médias de produtividade, onde foram colhidas manualmente as plantas em duas linhas 3,0 m lineares dentro da área útil da parcela. As plantas foram enfeixadas, identificadas e levadas para um terreiro, onde foram trilhadas em trilhadora mecânica estacionária, e posteriormente os grãos foram pesados em balança analítica com simultânea determinação da umidade pelo método da estufa de circulação forçada para correção da pesagem para 13\% (base úmida).

Os resultados foram submetidos ao teste de normalidade de Shapiro-Wilke, em seguida, à análise de variância ANOVA pelo teste $\mathrm{F}(p \leq$
$0,05)$. Havendo diferença significativa, as médias foram comparadas pela análise de regressão polinomial $(p \leq 0,05)$. A análise foi realizada utilizando o software estatístico AGROESTAT ${ }^{\oplus}$ (BARBOSA, 2010).

\section{Resultados e Discussão}

Observa-se que para MMS acumulada durante a condução do experimento em função das doses de $\mathrm{K}$ que houve diferença significativa apenas para o subprojeto com cultivo de sorgo (Tabela 1), no ano agrícola de 2012/13, onde os dados ajustaram-se a uma equação de regressão linear e negativa (Figura 2).

Tabela 1. Valores de $\mathrm{F}$ e médias obtidas na cultura do sorgo para os parâmetros massa de matéria seca (MMS), teor de $\mathrm{K}$ na palhada, retorno potencial e produtividade da cultura da soja implantada em sequência nos anos agrícolas de 2012/13 e 2013/14. Selvíria - MS.

\begin{tabular}{|c|c|c|c|c|c|c|c|c|c|c|}
\hline \multirow{3}{*}{$\begin{array}{c}\text { Tratamentos } \\
\text { Doses K }\end{array}$} & \multirow{2}{*}{\multicolumn{2}{|c|}{$\frac{\text { MMS }}{\mathrm{kg} \mathrm{ha}^{-1}}$}} & \multirow{2}{*}{\multicolumn{2}{|c|}{$\begin{array}{c}\begin{array}{c}\text { Teor de } \mathrm{K} \\
\text { (palhada) }\end{array} \\
\mathrm{g} \mathrm{kg}^{-1}\end{array}$}} & \multirow{2}{*}{\multicolumn{2}{|c|}{$\begin{array}{c}\begin{array}{c}\text { Retorno } \\
\text { potencial }\end{array} \\
\mathrm{kg} \mathrm{ha}^{-1}\end{array}$}} & \multirow{2}{*}{\multicolumn{2}{|c|}{$\begin{array}{c}\begin{array}{c}\text { Teor de K } \\
\text { (soja) }\end{array} \\
\mathrm{g} \mathrm{kg}^{-1}\end{array}$}} & \multirow{2}{*}{\multicolumn{2}{|c|}{$\begin{array}{c}\begin{array}{c}\text { Produtividade de } \\
\text { grãos }\end{array} \\
\text { kg ha }^{-1}\end{array}$}} \\
\hline & & & & & & & & & & \\
\hline & $12 / 13$ & $13 / 14$ & $12 / 13$ & $13 / 14$ & $12 / 13$ & $13 / 14$ & $12 / 13$ & $13 / 14$ & $12 / 13$ & $13 / 14$ \\
\hline 0 & 7806 & 6494 & 16,15 & 17,56 & 127,4 & 118,84 & 18,52 & 13,62 & 2303 & 2156 \\
\hline 35 & 8406 & 6972 & 18,22 & 19,81 & 154,0 & 139,03 & 18,00 & 15,16 & 2844 & 2615 \\
\hline 70 & 5379 & 6544 & 19,33 & 20,56 & 104,4 & 135,54 & 17,67 & 13,31 & 3267 & 2919 \\
\hline 120 & 4338 & 6825 & 17,63 & 19,16 & 78,2 & 136,25 & 17,62 & 13,56 & 2375 & 2473 \\
\hline \multicolumn{11}{|l|}{ F calculado } \\
\hline Doses K & $11,92^{*}$ & $0,111^{\text {ns }}$ & $3,332^{\text {ns }}$ & $2,647^{\text {ns }}$ & $8,251^{*}$ & $0,401^{\text {ns }}$ & $4,14^{*}$ & $0,95^{\mathrm{ns}}$ & $5,38^{*}$ & $25,63^{* *}$ \\
\hline CV (\%) & 17,31 & 20,45 & 8,12 & 8,14 & 19,41 & 21,9 & 2,26 & 12,43 & 14,34 & 4,93 \\
\hline Média & 6482 & 6709 & 17,83 & 19,27 & 116,0 & 132,41 & 17,95 & 13,91 & 2697 & 2541 \\
\hline $\mathbf{R L}$ & $18,67^{*}$ & $0,002^{\mathrm{ns}}$ & $7,72^{\text {ns }}$ & $5,65^{\text {ns }}$ & $1,17^{\text {ns }}$ & $0,463^{\mathrm{ns}}$ & $10,30 *$ & $0,29^{\mathrm{ns}}$ & $0,14^{\mathrm{ns}}$ & $14,26^{* *}$ \\
\hline RQ & $1,44^{\mathrm{ns}}$ & $0,28^{\text {ns }}$ & $0,114^{\text {ns }}$ & $0,36^{\text {ns }}$ & $5,461^{*}$ & $0,543^{\mathrm{ns}}$ & $2,13^{\text {ns }}$ & $0,30^{\text {ns }}$ & $15,02^{* *}$ & $60,52^{* *}$ \\
\hline
\end{tabular}

${ }^{\text {ns }}$, não significativo; ${ }^{*}$, significativo a $5 \% \mathrm{e}^{* *}$, significativo a $1 \%$.

12/13 e 13/14, respectivamente, correspondem aos anos agrícolas de 2012/13 e 2013/14. 
Figura 2. Médias e equação ajustada para massa de matéria seca produzida pelo sorgo em função das doses de K aplicadas. Selvíria - MS. 2012/13.

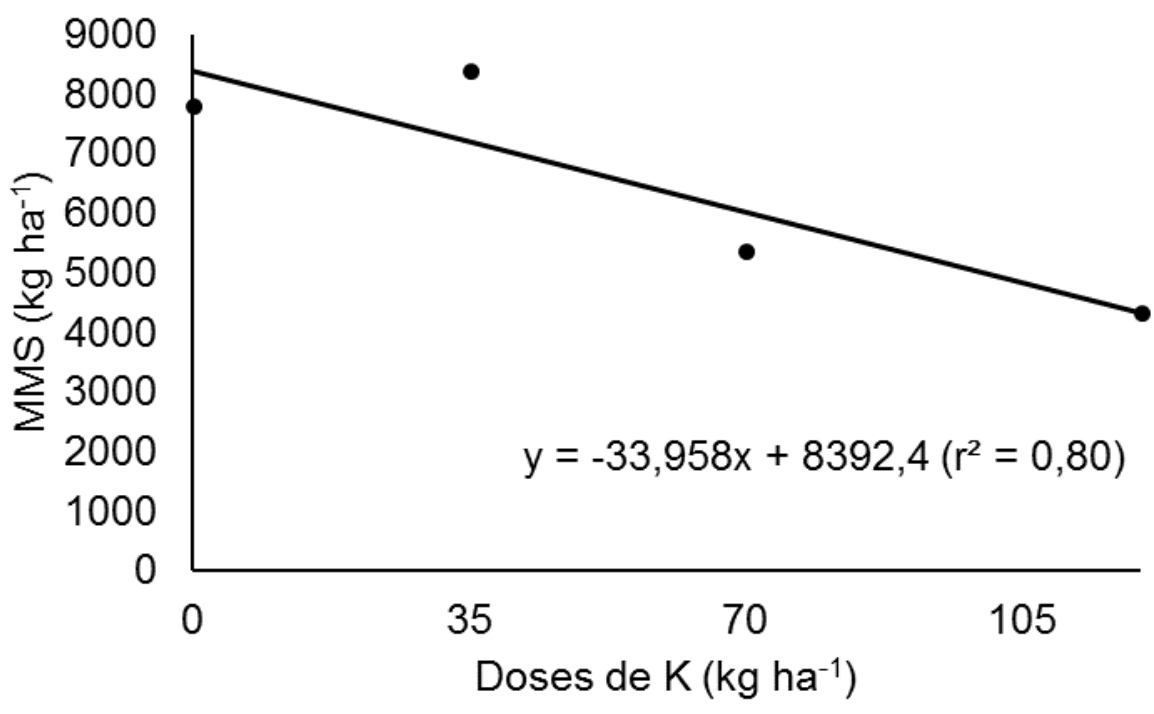

Em relação ao parâmetro MMS para o sistema sorgo-soja, as maiores produções de fitomassa obtidas sob sistema de plantio direto, mesmo quando menores doses de $\mathrm{KCl}$ são aplicadas, podem estar diretamente relacionadas com a maior proteção e capacidade do solo não revolvido acumular e ciclar nutrientes, principalmente o $\mathrm{K}$ na camada superficial do solo (NASCENTE et al., 2015).

A baixa produtividade de fitomassa do sorgo pode ser justificado pela semeadura tardia, devido a questões ambientais da região onde desenvolveu este trabalho, pois resultados de pesquisas na literatura elucidam que a época mais indicada para o plantio do sorgo é no período compreendido entre setembro a início de março, sendo quando a planta tem melhores condições de permanecer por mais tempo na fase vegetativa, acumulando mais carbono e, consequentemente, resultando em maiores quantidades de fitomassa, uma vez que esta planta é altamente sensível ao fotoperíodo (COSTA et al., 2015).

Nota-se então, que independente do sistema de sucessão, devido as variações climáticas e veranicos acentuados e estendidos durante os anos de condução do experimento, houve uma redução na produção de matéria seca das três culturas em razão ao esperado.
Em relação ao teor de $\mathrm{K}$ na palhada, não foi observada diferença estatística significativa para as plantas de cobertura em ambos anos de experimento. Possivelmente a adubação potássica nos três sistemas apresentou esse comportamento em razão a este nutriente não ser incorporado a cadeias carbônicas nos tecidos vegetais (FOLONI, 2008). Logo após a colheita ou senescência de plantas, este é rapidamente liberado para as camadas superficiais do solo, onde encontra-se em forma prontamente disponível para absorção radicular subsequente (BOSSOLANI et al., 2018).

Os valores referentes ao retorno potencial de $\mathrm{K}$ na cultura do sorgo mostraram diferença significativa no cultivo de $2012 / 13$ e as médias ajustaram-se a uma equação de regressão quadrática, apontando como dose de máxima eficiência técnica (DMET) 19,40 $\mathrm{kg} \mathrm{ha}^{-1}$ com acumulo de $136,44 \mathrm{~kg} \mathrm{ha}^{-1}$ de $\mathrm{K}$ disponível na palhada (Figura 3). Este parâmetro é uma medida direta que expressa a relação entre a quantidade de $\mathrm{K}$ acumulado na matéria seca produzida pela planta, em um hectare, que poderá vir a ser disponibilizado para a cultura instalada em sucessão. 
Figura 3. Médias e equação ajustada para retorno potencial de K na palhada de sorgo em função das doses de K aplicadas. Selvíria - MS. 2012/13.

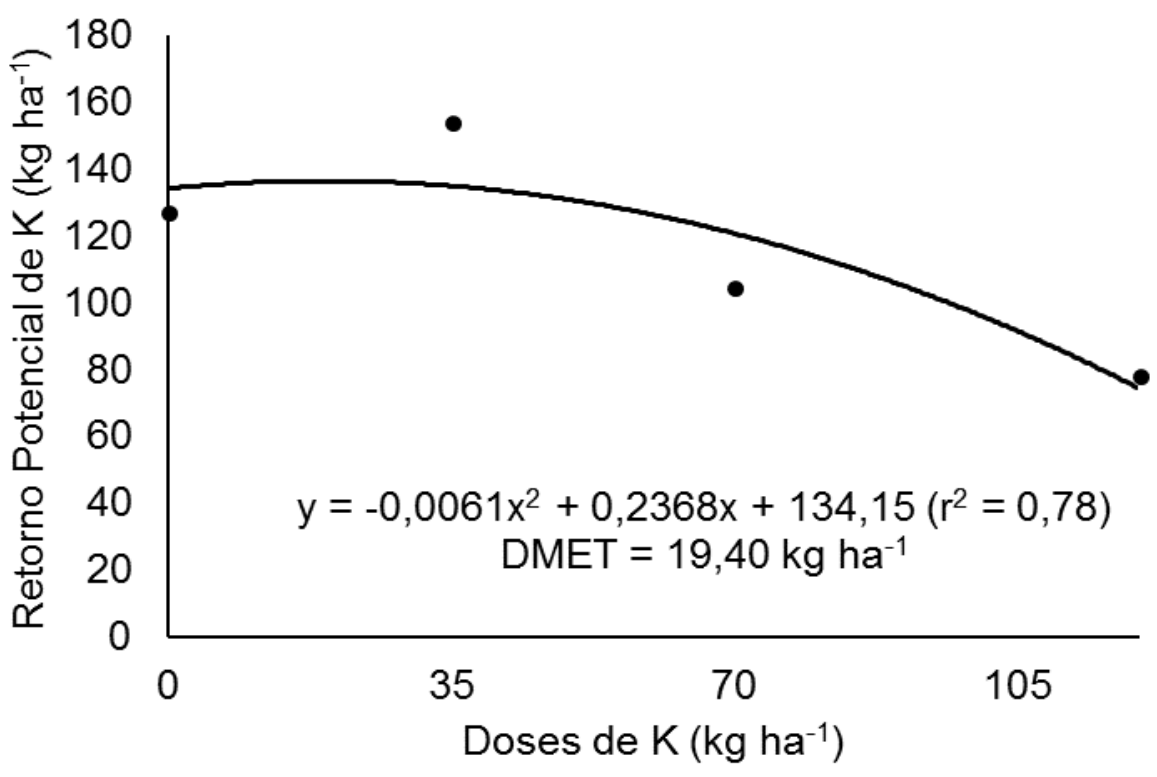

Aferiu-se também, diferença estatística em relação a teor de $\mathrm{K}$ foliar na soja, no qual os dados ajustaram-se a uma função linear negativa (Figura 4), similar ao efeito observado para MMS nesse subprojeto. Os valores observados para o sorgo, mesmo decrescentes em função das doses aplicadas, ainda estão dentro da faixa de suficiência para a cultura (COELHO et al., 2002).

Figura 4. Médias e equação ajustada para teor de $K$ nas folhas da soja em sucessão ao sorgo em função das doses de K aplicadas. Selvíria - MS. 2012/13.

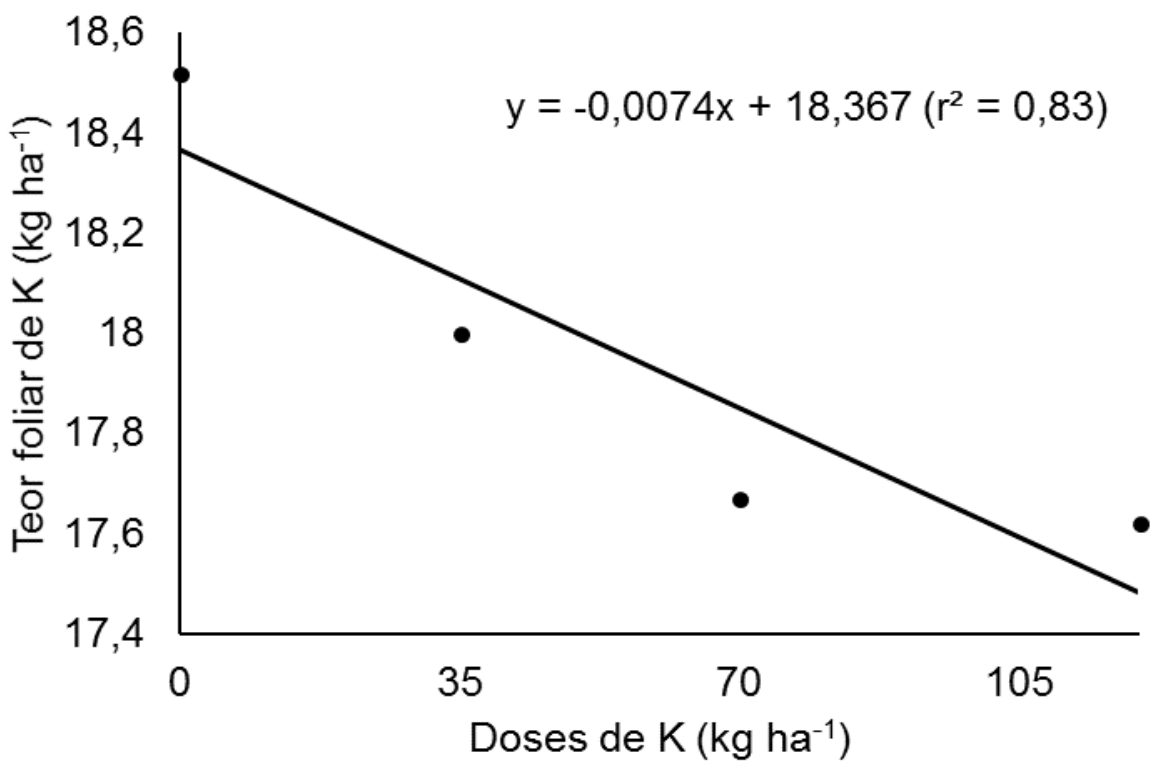

Aos desempenhos das médias de acumulo de $\mathrm{K}$ nas folhas de soja em sucessão ao sorgo com caráter de efeito negativo podem estar relacionadas a decomposição da palhada e rápida liberação de $\mathrm{K}$ não ter caráter estrutural, e no solo está constantemente submetido ao processo de lixiviação de bases, fazendo com que o acumulo deste nutriente na soja em sucessão seja prejudicado (KAYSER; ISSELSTEIN, 2005).

Na tabela 2 estão dispostos os resultados obtidos para as avaliações da sucessão com milho. Mesmo com uma produção média de 
palhada entre as épocas do experimento de $11085 \mathrm{~kg} \mathrm{ha}^{-1}$, sendo a maior dentre os experimentos, a MMS do milho não mostrou diferença significativa pelo teste $\mathrm{F}(p \leq 0,05)$. $O$ alto volume de fitomassa produzida pela cultura do milho mesmo não diferindo estatisticamente nem se ajustando a uma equação de regressão, ainda pode afirmar que essa quantia de acumulo de MMS é benéfico em vários sentidos ao solo, podendo agregar valor física, química e biologicamente a sua saúde e qualidade. Sendo uma cultura que é frequentemente submetida a processos de melhoramento genético, a seleção favorável da arquitetura de planta e área foliar promovem um melhor aproveitamento de luz, e logo, maior produção de fitomassa (SILVA et al., 2016).

Tabela 2. Valores de $\mathrm{F}$ e médias obtidas na cultura do milho para os parâmetros massa de matéria seca (MMS), teor de $\mathrm{K}$ na palhada, retorno potencial e produtividade da cultura da soja implantada em sequência nos anos agrícolas de 2012/13 e 2013/14. Selvíria - MS.

\begin{tabular}{|c|c|c|c|c|c|c|c|c|c|c|}
\hline \multirow{3}{*}{$\begin{array}{c}\text { Tratamentos } \\
\text { Doses K }\end{array}$} & \multirow{2}{*}{\multicolumn{2}{|c|}{$\frac{\text { MMS }}{\text { kg ha }^{-1}}$}} & \multirow{2}{*}{\multicolumn{2}{|c|}{$\begin{array}{c}\begin{array}{c}\text { Teor de K } \\
\text { (palhada) }\end{array} \\
\mathrm{g} \mathrm{kg}^{-1}\end{array}$}} & \multirow{2}{*}{\multicolumn{2}{|c|}{$\begin{array}{c}\begin{array}{c}\text { Retorno } \\
\text { potencial }\end{array} \\
\mathrm{kg} \mathrm{ha}^{-1}\end{array}$}} & \multirow{2}{*}{\multicolumn{2}{|c|}{$\frac{\text { Teor de K (soja) }}{\mathrm{g} \mathrm{kg}^{-1}}$}} & \multirow{2}{*}{\multicolumn{2}{|c|}{$\begin{array}{c}\begin{array}{c}\text { Produtividade de } \\
\text { grãos }\end{array} \\
\mathrm{kg} \mathrm{ha}^{-1}\end{array}$}} \\
\hline & & & & & & & & & & \\
\hline & $12 / 13$ & $13 / 14$ & $12 / 13$ & $13 / 14$ & $12 / 13$ & $13 / 14$ & $12 / 13$ & $13 / 14$ & $12 / 13$ & $13 / 14$ \\
\hline 0 & 9930 & 10884 & 14,27 & 14,25 & 139,66 & 155,54 & 17,06 & 14,25 & 2276 & 2299 \\
\hline 35 & 10078 & 12106 & 12,7 & 12,68 & 126,96 & 153,18 & 17,31 & 14,12 & 2531 & 2239 \\
\hline 70 & 13314 & 11551 & 13,2 & 13,18 & 174,34 & 156,83 & 17,8 & 13,31 & 3242 & 2701 \\
\hline 120 & 10111 & 10708 & 14,0 & 14,0 & 139,99 & 152,09 & 17,81 & 13,25 & 2452 & 2502 \\
\hline \multicolumn{11}{|l|}{ F calculado } \\
\hline Doses K & $4,35^{\mathrm{ns}}$ & $0,31^{\mathrm{ns}}$ & $0,46^{\mathrm{ns}}$ & $0,45^{\mathrm{ns}}$ & $1,83^{\mathrm{ns}}$ & $0,01^{\mathrm{ns}}$ & $1,71^{\mathrm{ns}}$ & $0,47^{\mathrm{ns}}$ & $6,14^{*}$ & $1,84^{\mathrm{ns}}$ \\
\hline CV (\%) & 14,47 & 20,16 & 15,76 & 15,78 & 20,64 & 22,48 & 3,24 & 11,23 & 13,05 & 12,7 \\
\hline Média & 10858 & 11312 & 13,54 & 13,53 & 145,24 & 154,41 & 17,49 & 13,73 & 2625 & 2435 \\
\hline $\mathbf{R L}$ & $0,62^{\mathrm{ns}}$ & $0,077^{\text {ns }}$ & $0,00^{\text {ns }}$ & $0,001^{\text {ns }}$ & $0,334^{\mathrm{ns}}$ & $0,01^{\mathrm{ns}}$ & $4,37^{\text {ns }}$ & $1,17^{\mathrm{ns}}$ & $1,58^{\mathrm{ns}}$ & $2,08^{\text {ns }}$ \\
\hline RQ & $2,26^{\mathrm{ns}}$ & $0,72^{\mathrm{ns}}$ & $1,14^{\mathrm{ns}}$ & $1,14^{\mathrm{ns}}$ & $1,00^{\mathrm{ns}}$ & $0,006^{\text {ns }}$ & $0,44^{\mathrm{ns}}$ & $0,03^{\mathrm{ns}}$ & $11,79^{* *}$ & $0,58^{\mathrm{ns}}$ \\
\hline
\end{tabular}

ns, não significativo; *, significativo a $5 \% \mathrm{e}^{* *}$, significativo a $1 \%$.

$12 / 13$ e 13/14, respectivamente, correspondem aos anos agrícolas de 2012/13 e 2013/14.

Segundo Massad et al. (2013), um dos grandes desafios para com a implantação de coberturas vegetais em sistema de plantio direto no Cerrado brasileiro é a conciliação com as condições climáticas no período de primaveraverão, onde nota-se alta taxa de decomposição do material vegetal no solo, devendo haver um aporte vegetal constante.

Os maiores valores de acumulo de $\mathrm{K}$ na palhada foram encontrados para $\mathrm{O}$ milheto (Tabela 3), com média geral de $27,7 \mathrm{~g} \mathrm{~kg}^{-1} \mathrm{em}$ 2013/13 e 25,55 $\mathrm{kg}^{-1}$ em 2013/14. Os altos valores de acumulo de $\mathrm{K}$ na palhada de milheto são constatados por vários autores. Este comportamento é uma característica intrínseca desta espécie vegetal segundo Silva e Lazarini (2014), e pode levar a uma alta ciclagem deste nutriente, caracterizando assim, a sua palhada como um reservatório expressivo de $\mathrm{K}$, em curto prazo, em áreas de plantio direto (FOLONI et al., 2016). É de importância ressaltar que os resultados obtidos nesta avaliação, por não serem referentes ao os teores foliares do nutriente em questão, não se deve fazer a comparativa com faixas de suficiência nas culturas em estudo, disponíveis na literatura. 
Tabela 3. Valores de $\mathrm{F}$ e médias obtidas na cultura do milheto para os parâmetros massa de matéria seca (MMS), teor de $\mathrm{K}$ na palhada, retorno potencial e produtividade da cultura da soja implantada em sequência nos anos agrícolas de 2012/13 e 2013/14. Selvíria - MS.

\begin{tabular}{|c|c|c|c|c|c|c|c|c|c|c|}
\hline \multirow[t]{2}{*}{ Tratamentos } & \multicolumn{2}{|c|}{ MMS } & \multicolumn{2}{|c|}{$\begin{array}{l}\text { Teor de K } \\
\text { (palhada) }\end{array}$} & \multicolumn{2}{|c|}{$\begin{array}{l}\text { Retorno } \\
\text { potencial }\end{array}$} & \multicolumn{2}{|c|}{ Teor de K (soja) } & \multicolumn{2}{|c|}{$\begin{array}{c}\text { Produtividade } \\
\text { de grãos }\end{array}$} \\
\hline & \multicolumn{2}{|c|}{$\mathrm{kg} \mathrm{ha}^{-1}$} & \multicolumn{2}{|c|}{$\mathrm{g} \mathrm{kg}^{-1}$} & \multicolumn{2}{|c|}{$\mathrm{kg} \mathrm{ha}^{-1}$} & \multicolumn{2}{|c|}{$\mathrm{g} \mathrm{kg}^{-1}$} & \multicolumn{2}{|c|}{$\mathrm{kg} \mathrm{ha}^{-1}$} \\
\hline Doses K & $12 / 13$ & $13 / 14$ & $12 / 13$ & $13 / 14$ & $12 / 13$ & $13 / 14$ & $12 / 13$ & $13 / 14$ & $12 / 13$ & $13 / 14$ \\
\hline 0 & 5563 & 5343 & 27,21 & 25,91 & 125,26 & 136,91 & 13,87 & 14,93 & 2274 & 2225 \\
\hline 35 & 4583 & 5269,5 & 27,82 & 26,5 & 153,84 & 142,63 & 18,16 & 17,06 & 2922 & 2526 \\
\hline 70 & 5918 & 6066 & 26,95 & 24,06 & 151,44 & 149,96 & 18,00 & 15,75 & 2672 & 2493 \\
\hline 120 & 5918 & 6274,2 & 28,84 & 25,75 & 169,54 & 156,51 & 17,58 & 15,68 & 2220 & 2257 \\
\hline \multicolumn{11}{|l|}{ F calculado } \\
\hline Doses K & $0,948^{\text {ns }}$ & $0,762^{\text {ns }}$ & $0,489^{\text {ns }}$ & $0,936^{\mathrm{ns}}$ & $1,596^{\mathrm{ns}}$ & $0,353^{\text {ns }}$ & $10,59^{* *}$ & $0,71^{\mathrm{ns}}$ & $3,92^{*}$ & $0,45^{\mathrm{ns}}$ \\
\hline CV (\%) & 18,27 & 18,15 & 8,66 & 8,47 & 19,37 & 19,64 & 7,39 & 13,21 & 13,39 & 19,61 \\
\hline Média & 5425,7 & 5738,1 & 27,7 & 25,55 & 150,02 & 146,5 & 16,9 & 15,85 & 2522 & 2375 \\
\hline $\mathbf{R L}$ & $0,47^{\text {ns }}$ & $2,35^{\mathrm{ns}}$ & $0,66^{\mathrm{ns}}$ & $0,25^{\mathrm{ns}}$ & $3,99^{\text {ns }}$ & $1,050^{\mathrm{ns}}$ & $13,29^{* *}$ & $0,02^{\text {ns }}$ & $0,61^{\text {ns }}$ & $0,00^{\text {ns }}$ \\
\hline $\mathbf{R Q}$ & $0,20^{\text {ns }}$ & $0,00^{\text {ns }}$ & $0,29^{\text {ns }}$ & $0,513^{\mathrm{ns}}$ & $0,20^{\text {ns }}$ & $0,00^{\text {ns }}$ & $15,27^{* *}$ & $0,89^{\text {ns }}$ & $9,50^{*}$ & $1,28^{\text {ns }}$ \\
\hline
\end{tabular}

ns, não significativo; *, significativo a $5 \% \mathrm{e}^{* *}$, significativo a $1 \%$.

12/13 e 13/14, respectivamente, correspondem aos anos agrícolas de 2012/13 e 2013/14.

Para a avaliação dos teores foliar de $\mathrm{K}$ na cultura da soja, as médias de modo geral foram maiores no primeiro ano de experimento. Verifica-se que para a área com milheto, houve diferença significativa, onde o ajuste quadrático foi constatado, tendo assim, como ponto de máxima, a dose de $73,37 \mathrm{~kg} \mathrm{ha}^{-1}$ (Figura 5), acumulando $18,46 \mathrm{~g} \mathrm{~kg}^{-1}$. Em função ao alto acumulo de $\mathrm{K}$ na palhada desta cultura, espera-se que a cultura sucessora se beneficie na absorção deste nutriente (SOUZA FILHO et al., 2016), beneficiando seu desenvolvimento, sem a necessidade de suplementação mineral nessa fase do sistema.

Figura 5. Médias e equação ajustada para teor de $\mathrm{K}$ nas folhas da soja em sucessão ao milheto em função das doses de K aplicadas. Selvíria - MS. 2012/13.

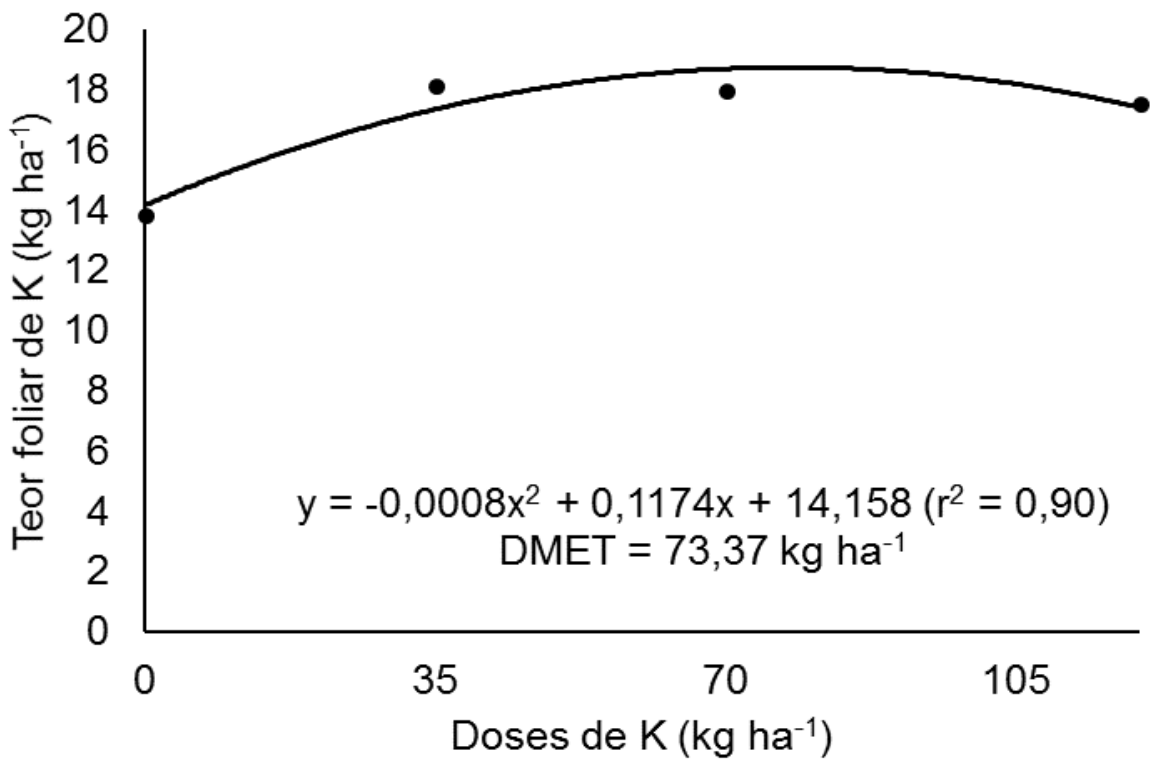


As médias de produtividade de grãos obtidas na cultura da soja apontaram diferença significativa para todas as três coberturas no ano agrícola de 2012/13 (Figura 6, 7 e 8), tendo como máximo valor observado entre os subprojetos, $3160 \mathrm{~kg} \mathrm{ha}^{-1} \mathrm{com}$ a utilização de $62,71 \mathrm{~kg} \mathrm{ha}^{-1} \mathrm{em}$ área de sorgo como antecessor, seguido do milho com $3004 \mathrm{~kg} \mathrm{ha}^{-1}$ na dose de 67,67 kg ha ${ }^{-1}$ de $\mathrm{K}$ e milheto com máxima de $2837 \mathrm{~kg} \mathrm{ha}^{-1}$ com a dose de $56,29 \mathrm{~kg} \mathrm{ha}^{-1}$. Segundo a Companhia Nacional de Abastecimento - CONAB (2018), a produtividade média nacional projetada em fevereiro é de $3185 \mathrm{~kg} \mathrm{ha}^{-1}$, estando os dados obtidos por este trabalho, no primeiro ano, próximos a esse valor para o sistema com sorgo e milho.

Figura 6. Médias e equação ajustada para produtividade da soja em sucessão ao sorgo em função das doses de K aplicadas. Selvíria - MS. 2012/13.

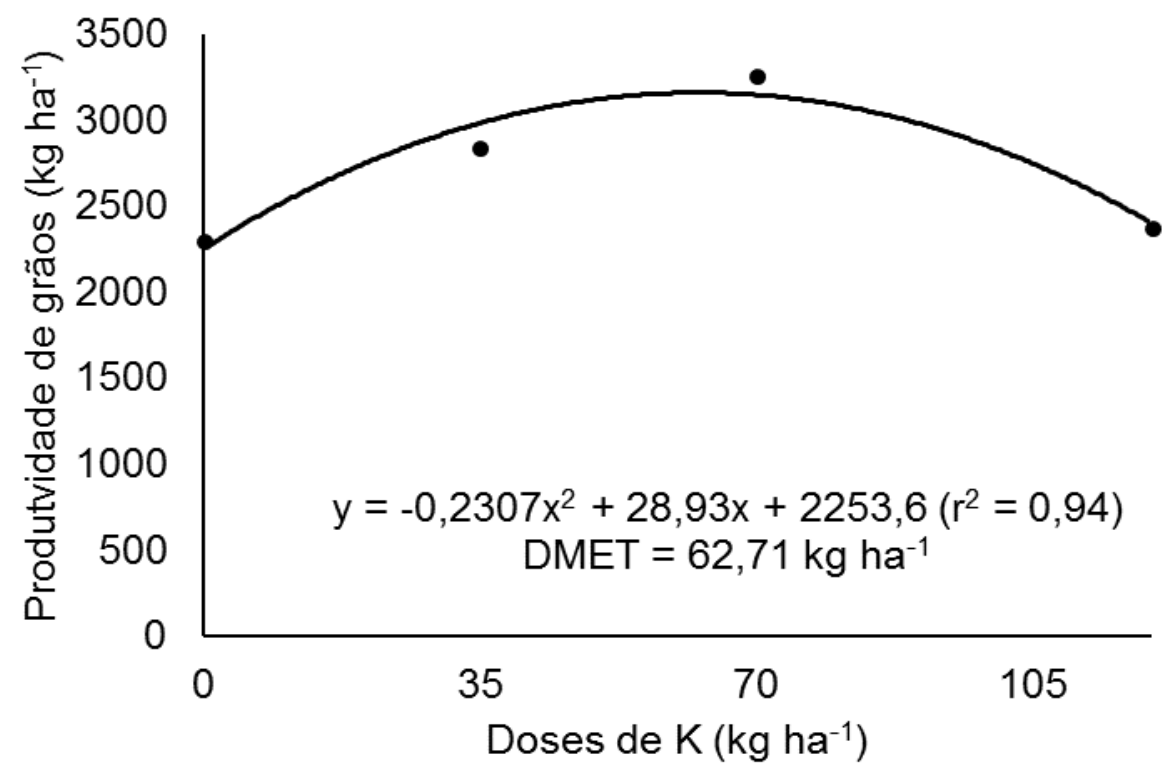

Figura 7. Médias e equação ajustada para produtividade da soja em sucessão ao milho em função das doses de K aplicadas. Selvíria - MS. 2012/13.

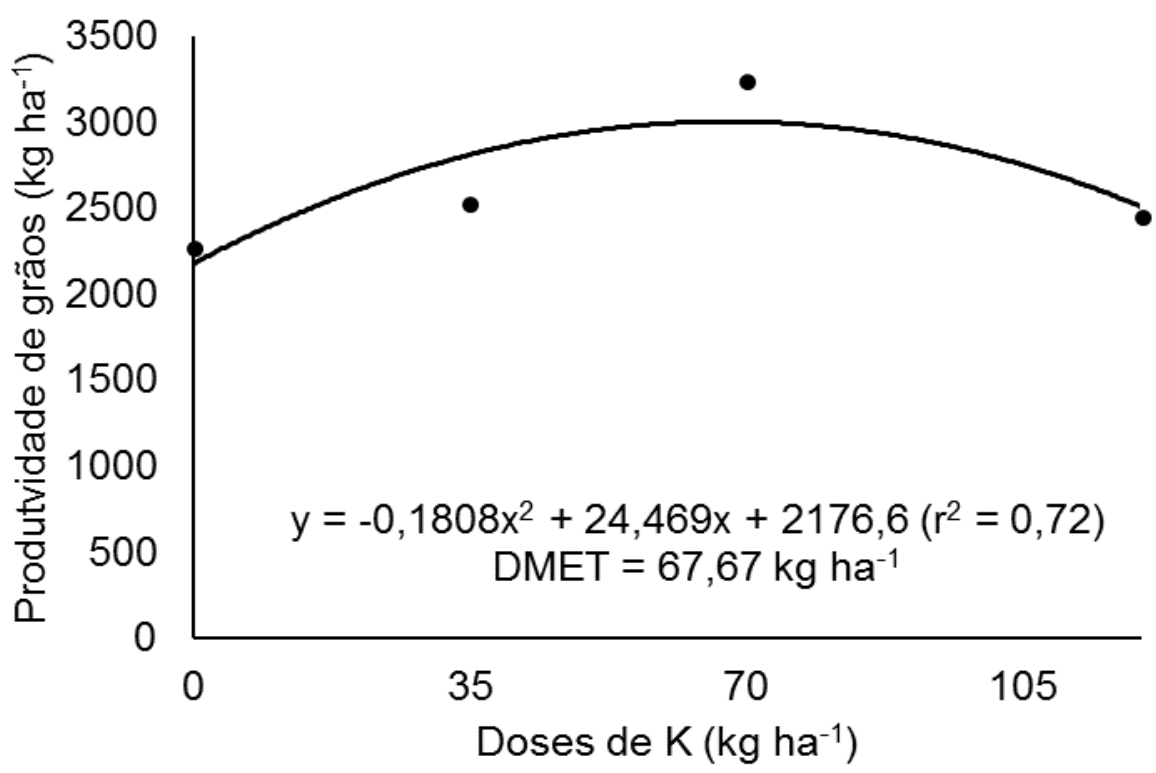


Figura 8. Médias e equação ajustada para produtividade da soja em sucessão ao milheto em função das doses de K aplicadas. Selvíria - MS. 2012/13.

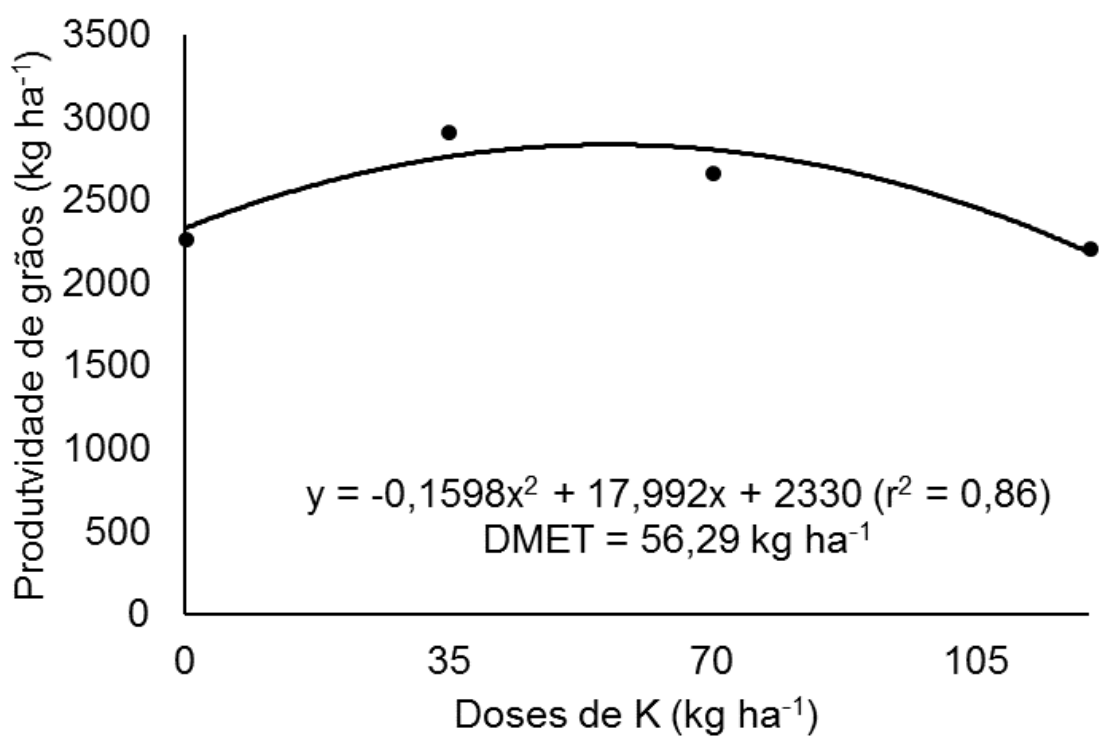

$O$ alto rendimento médio de grãos na sucessão milho-soja possivelmente foi em função do alto volume de palhada produzida pela cultura, melhorando as condições de desenvolvimento da soja, tanto por ciclagem de nutrientes como estabilidade e manutenção da umidade e temperatura do solo (SOUZA et al., 2016).

O subprojeto de sucessão sorgo-soja mostrou resultados satisfatórios para a produtividade de grãos, mesmo quando baixas quantidades de material vegetal no solo estavam presentes, e, consequentemente, um menor retorno potencial de $\mathrm{K}$ nesta área, e ainda assim foram verificadas as maiores produtividades. Isso pode estar relacionado a uma alta taxa de decomposição dos resíduos vegetais condicionada pelo clima, e consequentemente maior velocidade de liberação de outros nutrientes da matéria orgânica, como N, S, Zn e B (LUSTOSA FILHO, 2017; TAUK, 2018), favorecendo assim o aumento produtivo da cultura da soja.

Em 2013/14 constatou-se apenas diferença estatista para o cultivo de sorgo (Figura 9), sendo a DMET 69,86 $\mathrm{kg} \mathrm{ha}^{-1}$, produzindo $2864 \mathrm{~kg} \mathrm{ha}^{-1} \mathrm{de}$ grãos.

Figura 9. Médias e equação ajustada para produtividade da soja em sucessão ao sorgo em função das doses de K aplicadas. Selvíria - MS. 2013/14.

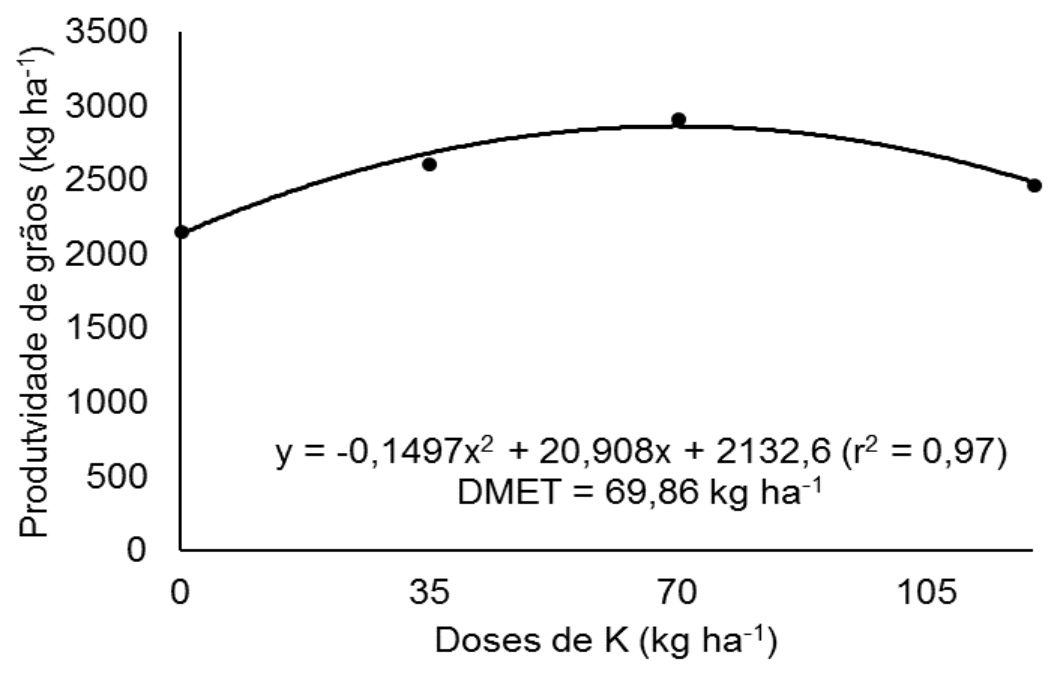




\section{Conclusões}

O milho inserido no sistema demostrou alta produção de matéria seca em ambos os anos na aplicação de $70 \mathrm{~kg} \mathrm{ha}^{-1}$ de $\mathrm{KCl}$.

Para acumulo de $\mathrm{K}$, tanto na palhada como em folhas de soja em sucessão, o milheto destacou-se, em ambos os anos ao se utilizar a dose de $35 \mathrm{~kg} \mathrm{ha}^{-1}$ de $\mathrm{KCl}$.

A sucessão sorgo-soja propiciou maior produtividade de grãos quando submetido a doses de $70 \mathrm{~kg} \mathrm{ha}^{-1}$.

Os teores de $\mathrm{K}$ nas plantas de soja não foram influenciados positivamente em função das doses aplicadas, em nenhuma das plantas de cobertura.

\section{Referências}

BARBOSA, J. C.; MALDONADO JÚNIOR, W. AgroEstat: sistema para análises estatísticas de ensaios agronômicos. Jaboticabal: Unesp, 2010.

BOSSOLANI, J. W.; LAZARINI, E.; de SOUZA, L. G.; PARENTE, T. D. L.; CAIONI, S.; BIAZI, N. Q. D. Potassium doses in previous crops and effect on soybean in succession. Revista Brasileira de Engenharia Agrícola e Ambiental, v. 22, n. 2, p. 90-94, 2018.2 DOI: http://dx.doi.org/10.1590/1807-

1929/agriambi.v22n2p90-94.

COELHO, A. M.; WAQUIL, J. M.; KARAM, D.; CASELA, C. R.; RIBAS, P. M. Seja o doutor do seu sorgo. Informações Agronômicas, v. 14, n. 100, p. 1-12, 2002.

COSTA, N. R.; ANDREOTTI, M.; ULIAN, N. A.; COSTA, B. S.; PARIZ, C. M.; CAVASSANO, F. A.; TEIXEIRA FILHO, M. C. M. Produtividade da soja sobre palhada de forrageiras semeadas em diferentes épocas e alterações químicas no solo. Revista Brasileira de Ciências Agrárias, v. 10, n. 1, 2015.

https://doi.org/10.5039/agraria.v10i1a3842.

CONAB. Acompanhamento da safra brasileira de grãos. Sexto levantamento. v.5, n.6, 2018.

EMBRAPA. Sistema Brasileiro de Classificação dos Solos. 3. ed. Brasília: Embrapa, 2013. .

FOLONI, J. S. S.; CATUCHI, T. A.; DE MORAES BARBOSA, A.; CALONEGO, J. C.; TIRITAN, C. S. Acúmulo de nutrientes e relação $\mathrm{C} / \mathrm{N}$ em diferentes estádios fenológicos do milheto submetido à adubação nitrogenada. Revista Agro@ mbiente On-line, v. 10, n. 1, p. 1-9, 2016. DOI: $\quad$ http://dx.doi.org/10.18227/19828470ragro.v10i1.2798.

FOLONI, J. S. S; ROSOLEM, C. A. Produtividade e acúmulo de potássio na soja em função da antecipação da adubação potássica no sistema plantio direto. Revista Brasileira de Ciência do Solo, v.32, n.4, 2008. https://doi.org/10.1590/S0100$\underline{06832008000400019}$

JONES JÚNIOR, J. B.; WOLF, B.; MILLS, H. A. Plant analysis handbook, a pratical sampling, preparation, analysis, and interpretation guide. Georgia, USA: Micro-macro, 1991. p. 35-38.

KAYSER, M.; ISSELSTEIN, J. Potassium cycling and losses in grassland systems: a review. Grass and Forage Science, v.60, n.3, p.213-224, 2005. DOI: https://doi.org/10.1111/j.1365-

2494.2005.00478.x.

KAWAVATA, C. K. H.; KENT, C.,;FATECHA FOIS, D. A.; COPPO, J. C.,;NETO, A. Influence of doses and of two sources of potassium in the maize root system and in the electrical conductivity in the soil. Investigación Agraria, v. 19, n. 1, p.28-34, 2017.

DOI:

http://dx.doi.org/10.18004/investig.agrar.2017.ju nio.28-34.

KLUTHCOUSKI, J.; FANCELLI, A. L.; DOURADO NETO, D.; RIBEIRO, C. M.; FERRARO, L. A. Manejo do solo e o rendimento de soja, milho, feijão e arroz em plantio direto. Scientia Agricola, v.57, n.1, p.97-104, 2000.

LUSTOSA FILHO, J. F.; NÓBREGA, J. C. A.; NETO, A. E. F.; SILVA, C. A.; NÓBREGA, R. S. A.; PRAGANA, R. B.; $G M A C H, M$. R. Disponibilidade nutrientes e teor de matéria orgânica sob diferentes sistemas de uso e manejo. Revista Brasileira de Ciências Agrárias (Agrária), v.12, n.4, p.475-483, 2017. DOI:

http://dx.doi.org/10.5039/agraria.v12i4a5481.

NASCENTE, A. S; STONE, L. F.; CRUSCIOL, C. A. C. Soil chemical properties affected by cover crops under no-tillage system. Revista Ceres, v.62, n.4, p.401-409, 2015. DOI: http://dx.doi.org/10.1590/0034737X201562040010. 
MALAVOLTA, E. Avaliação do estado nutricional das plantas: princípios e aplicações/Eurípedes Malavolta, Godofredo Cesar Vitti, Sebastião Alberto de Oliveira. 2. ed. Piracicaba: Potafos, 1997.

MASSAD, M. D.; DUTRA, T. R.; DE OLIVEIRA, J. C.; SARMENTO, M. F. Q. Comportamento de leguminosas anuais utilizadas como adubos verdes na região semiárida mineira. Revista Acadêmica: Ciência Animal, v.11, n.S2, 2013. https://doi.org/10.7213/academica.10.S02.AO14

PARENTE, T. L.; LAZARINI, E.; CAIONI, S.; DE SOUZA, L. G. M.; PIVETTA, R. S.; BOSSOLANI, J. W. Potássio em cobertura no milho e efeito residual na soja em sucessão. REVISTA AGRO@ MBIENTE ON-LINE, v.10, n.3, p.193-200, 2016. DOI: http://dx.doi.org/10.18227/1982-

8470ragro.v10i3.3258.

PIRES, F. R.; DE ASSIS, R. L.; DE OLIVEIRA PROCÓPIO, S.; SILVA, G. P.; MORAES, L. L.; RUDOVALHO, M. C.; BÔER, C. A. Manejo de plantas de cobertura antecessoras à cultura da soja em plantio direto. Ceres, v.55, n.2, 2015.

PORTUGAL, J. R.; PERES, A. R.; RODRIGUES, R. A. F. 2015. Aspectos climáticos no feijoeiro. In: ARF, O.; LEMOS, L.B.; SORATTO, R.P.; FERRARI, S. (Eds.) Aspectos gerais da cultura do feijão (Phaseolus vulgaris L.). Botucatu: FEPAF, p. 65-75.

SILVA, A. F.; LAZARINI, E. Doses e épocas de aplicação de potássio na cultura da soja em sucessão a plantas de cobertura. Semina: Ciências Agrárias, v.35, n.1, 2014. https://doi.org/10.5433/1679-

$\underline{0359.2014 v 35 n 1 p 179}$

SILVA, M. P.; ARF, O.; SÁ, M. E. DE; ABRANTES, F. L.; BERTI, L. F.; SOUZA, L. C. D.; ARRUDA, N.; Palhada, teores de nutrientes e cobertura do solo por plantas de cobertura semeadas no verão para semeadura direta de feijão. Revista Agrarian, Dourados, v.7, n.24, p.233-243, 2014.

SILVA, M. A.; FERREIRA, W. M.; ANDRADE, V.; COSTA, J. Influência das condições microclimáticas no crescimento do milho BR 106 cultivado sob sementeira direta. Revista de Ciências Agrárias, v.39, n.3, p.383-394, 2016. DOI: http://dx.doi.org/10.19084/RCA15117.
SOUSA, S. F. G. Avaliação da cultura do milho e da decomposição da palhada submetida à Hormesis. 2013. 64 f. Dissertação (Mestrado em Agronomia) - Universidade Estadual Paulista Botucatu, 2013.

SOUZA, E. D.; CARNEIRO, M. A. C.; BARBOSA PAULINO, H.; RIBEIRO, D. O.; BAYER, C.; ROTTA, L. R. Matéria orgânica e agregação do solo após conversão de "campos de murundus" em sistema plantio direto. Pesquisa Agropecuária Brasileira, v.51, n.9, p.1194-1202, 2016 https://doi.org/10.1590/s0100204x2016000900019.

SOUZA FILHO, A. L.; DE OLIVEIRA, F. H. T.; PRESTON, W.; DA SILVA, G. F.; DE CARVALHO, S. L. Adubação nitrogenada e fosfatada em milho verde cultivado em sucessão ao meloeiro. Horticultura Brasileira, v.34, n.3, 2016. DOI: https://doi.org/10.1590/hb.v34i3.510.

TAUK, S. M. Biodegradação de resíduos orgânicos no solo. Revista Brasileira de Geociências, v. 20, n.1-4, p.299-301, 2018. https://doi.org/10.25249/0375-7536.1990299301

TORRES, J. L. R.; PEREIRA, M. G. Dinâmica do potássio nos resíduos vegetais de plantas de cobertura no Cerrado. Revista Brasileira de Ciência do Solo, v.32, n.4, p.1609-1618, 2008. https://doi.org/10.1590/S0100$\underline{06832008000400025}$

TORRES, J. L. R.; PEREIRA, M. G.; LARA DE ASSIS, R.; MENEZES DE SOUZA, Z. Atributos físicos de um Latossolo Vermelho cultivado com plantas de cobertura, em semeadura direta. Revista Brasileira de Ciência do Solo, v.39, n.2, 2015. https://doi.org/10.1590/01000683rbcs20140597 